\title{
Covid-19 and ethnicity: it's too early to point to healthcare provider attitudes as a cause of poorer outcomes
}

\author{
Anthony D Dimarco clinical fellow in inherited cardiovascular disease
}

Barts Heart Centre, St Bartholomew's Hospital, London EC1A 7BE, UK

I was perturbed to read Partha Kar's article in which he postulates that the poorer outcomes seen in patients from ethnic minority backgrounds may stem from these people not receiving the same level of care and attention during treatment for covid-19 as the rest of the population. ${ }^{1}$ My experience does not reflect this conclusion. I, along with many of my colleagues both within my organisation and across the country, have been on secondment from our usual roles to provide support within significantly expanded intensive care services. In keeping with the general trend, most patients I cared for were from black, Asian, or minority ethnic (BAME) backgrounds. Several were healthcare workers. We provided the highest possible quality and level of care for these patients including the prolonged use of extracorporeal membrane oxygenation treatment. I am pleased to say that many are now in the recovery phase, having survived critical illness. At no point was the ethnicity of the patient a perceivable barrier to initiating or maintaining this treatment.

We do know that the SARS-CoV-2 virus infects its host through the angiotensin converting enzyme 2 receptor. $^{2}$ In view of differing responses of BAME people to treatment with angiotensin 2 receptor antagonists it's possible that there may be a biological basis to account for the imbalance in infection rates between ethnicities.

Although I am not naïve enough to believe that there is no possibility of racism existing within the NHS, in my opinion it is too early to point to healthcare provider attitudes as a cause of the disparity in covid-19 illness.

Competing interests: None declared.

Kar P. Partha Kar: Covid-19 and ethnicity: why are all our angels white?BMJ 2020;369:m1804. 10.1136/bmi.m1804 32371436

2 Guzik TJ, Mohiddin SA, Dimarco A, et al. COVID-19 and the cardiovascular system: implications for risk assessment, diagnosis, and treatment options. Cardiovasc Res 2020;cvaa106. 10.1093/cvr/cvaa106. 32352535

Published by the BMJ Publishing Group Limited. For permission to use (where not already granted under a licence) please go to http://group.bmj.com/group/rights-licensing/ permissions 